\title{
COMPUSTRESS: THE FEAR OF COMPUTER USAGE AMONG COLLEGE OF BUSINESS ADMINISTRATION STUDENTS
}

Nick Nykodym, Ph.D., University of Toledo

Jack L. Simonetti, D.B.A., University of Toledo

Joseph C. Christen, M.O.D., University of Toledo

\begin{abstract}
This study explores the area of computer apprehension among College of Business Administration students at a midwestern university. The fear of computer usage has been termed Cyberphobia, Computer Apprehension, Computerphobia, Computer Anxiety, Computer Vertigo and Terminal Anxiety. The authors have coined the word: Compustress. A review of the literature revealed that little has been published on this subject. A variety of anecdotal data are provided by a number of authors. These brief data are explored. It was noted that business students may experience "terminal shock" when they are appraised of the widespread use of computers in their field. Data were collected from College of Business Administration majors on level of computer apprehension, number of hours of computer usage and number of hours of computer training. Results indicate that the higher the number of hours of computer usage and training, the lower the computer apprehension.
\end{abstract}

\section{Introduction}

Stress and anxiety are reality of university and campus life. However, the nature and dynamics of these anxieties have not been completely explored. Perspective can be obtained by consulting the now classic psychosomatic research of Holmes and Rahe (1967), based on the "Social Readjustment Rating Scale." Their scale consisted of a list of the most significant "Life Events" which relate to anxiety, personal stress coping, health and fitness. The sometimes popular notion that student life is carefree is largely dispelled by inspection of the Life Events Rating Scale (Holmes and Rahe, 1967). For example, the following "Social Readjustment" factors all affect student life: change in work hours/conditions, change in residence, change in schools, change in recreation, change in church activities, change in social activities, change in sleeping habits, change in number of family get-togethers, change in eating habits, change in financial state, change in line of work, beginning/end of school, change in living conditions, and revision of personal habits. The compounded impact of these social readjustment and life events factors must account for some of the anxiety level in campus existence.

One area of student anxiety that has been documented is that of Communication Apprehension (CA). Samples of college and university students reveal that ten to twenty percent suffer from high Communication Apprehension and as many as forty percent have a Communication Apprehension problem that has some impact on their ability to communicate (Nykodym and Ruud, 1985). Communication Apprehension is severe, and has even been termed a "handicap" (Nykodym and Ruud, 1985). It is possible to reduce student Communication Apprehension levels and thereby increase their effectiveness in the work environment (Nykodym and Simonetti, 1978). In addressing communication apprehension, it was found that an individual program of self-awareness assess- 
ment was an integral part of addressing this anxiety. An intervention strategy was developed to integrate knowledge, skill and personal experience, providing each individual with a variety of effective styles for dealing with their personal communication apprehension (Nykodym and Ruud, 1985).

Little data are available to provide similar insights into student Compustress -- the fear of computers. Some anecdotal data indicates that business students are under a great deal of pressure to computerize and may even experience "terminal shock" (James, 1982, p. 37).

Whether fear of computers is called Compustress, cyberphobia, computerphobia or another title, it is a subject that has not commanded the attention of scholarly journals. In widely respected journals little research has appeared on the subject of Computer Apprehension. Even anecdotal data are scant. Some perspective on Compustress is provided by Bralobe (1985), who has estimated that about ninety percent of the nation's professional managers are computer illiterates. Wysocki (1979) noted that many high-level executives feel "terrified" of their new computer terminals. James estimates that thirty percent of the nation's office workers are not comfortable with media display terminals, word processors or even the most basic computer terminology (bits and bytes). Furthermore, nearly one third of corporate managers displayed computer anxiety as revealed by galvanic skin response machines (1985). A similar finding by Paul (1982, p.1414) indicates that approximately thirty percent of business and industry experience some form of computerphobia. Paul also shares the anecdotal examples of an office worker who tried to sabotage his computer by dumping coffee and pencil shavings into his console, and of a policeman who resolved his computer anxiety by shooting the computer in his patrol car (1982).

Professionals in the work place are not free from Compustress. Friedman studied managers and discovered that they experienced anxiety about technologies such as computer usage. Health care professionals were the focus of a study by Grobe (1984). She used the term "computer cowardice" to describe a common apprehension among nurses (1984, p. 233). Grobe observed that computer anxiety arises from the lack of familiarity and understanding of how computers can be used in the work environment (1984, p. 233). Recent work by Carroll, 1988 confirms the "tough job of training computerphobic managers."

This present work focuses specifically on two factors that can reduce Compustress experience on the computer, and education on computer usage. It expends an earlier survey of 130 middle-level managerial and staff personnel in a variety of business organizations (Nykodym, Simonetti, \& Christen, 1988). That study revealed a significant inverse relationships between the amount of computer experience and computer apprehension, and between computer apprehension and the amount of education on computer usage (1988). This present study addresses the same questions, but examines the effects of relevant experience and education on Compustress among College of Business Administration students. The following exploratory research hypotheses were investigated:

H1: There will be a statistically significant correlation between the amount of computer experience and computer apprehension among College of Business Administration students.

$\mathrm{H} 2$ : There will be a statistically significant correlation between computer apprehension and the amount of education and computer usage among College of Business Administration students.

\section{Measuring Instrument}

The measuring instrument used in this study was the "Personal Report of Computer Apprehension" (Nykodym, Simonetti, \& Christen, 1988). Instrument development used data collected by interview and open-ended surveys on the topic of computer apprehension. The subjects consisted of a wide range of organizational managerial and staff personnel in a variety of organizational settings. The research included seventy-five interviews as well as five hundred and fifty surveys on the subject of computer apprehension (Compustress). The sampling frame was a cross section of industries listed by the Chamber of Commerce of a large midwestern city. Computer apprehension was found to be particularly high in areas such as co-worker, superior and extra-organizational evaluation of the employee's computer work. Employees were also concerned about "doing their writing", "doing computations" and "doing other work on a computer." The instrument is a twenty-item survey questionnaire which 
offers choices of strongly agree, agree, neutral, disagree, and strongly disagree. Face (content) validity was established by straightforward questions on computer apprehension that was discovered in the survey data. An analysis of the instrument via an internal consistency reliability coefficient revealed a score of +.89 .

\section{Sample and Design}

Data were collected from 194 College of Business Administration students at a midwestern university. Data were collected during the administration of a variety of other questionnaires, surveys and training exercises. A large amount of other data were being collected and discussed. Since this was standard procedure for the students, it is highly unlikely that a testing effect could have occurred.

\section{Statistical Analysis}

Self reports on level of computer apprehension as well as computer experience and education on computer usage were collected. A multiple regression analysis was used to study the relationship between the dependent variable of computer apprehension and the independent variables of number of hours of computer usage and number of hours of computer training. Additional tests of significance were conducted on variables of experience (user hours and computer training). The alpha level was set at .05 .

\section{Results}

Statistically significant results were achieved on the multiple regression analysis (significant at the .0001 level, see table 1). Additional tests revealed statistically significant results for user hours (significant at the .0001 level) and hours of computer training (significant at .02 level, see table 2).

The results confirm the research hypotheses:

H1: There will be a statistically significant relationship between the amount of computer experience and apprehension in College of Business Administration students.

$\mathrm{H} 2$ : There will be a statistically significant relationship between computer apprehension and the amount of education in computer usage among College of Business Administration students.

\section{Discussion}

While it is possible to generalize with accuracy only about the sample collected among college of business administration students at this university, however, some generalizations about other college of business administration students are possible. It would be logical to assume that the number of hours of computer experience as well as the number of hours of computer training would statistically relate to computer apprehension. However, additional data needs to be collected to extend the generalization of the hypotheses. Future recommendations would include a larger sample as well as greater diversity of students and universities.

\section{Recommendations for Future Training}

A variety of options exist and could effectively reduce computer apprehension. One option would be to focus on both individual and group behavioral change. Individual behavior change might focus on increased knowledge of one's computer apprehension level and its impact on one's productivity and marketability. Students could be appraised of the need to be more competitive in the job search or promotion dynamics of organizations (Schwartz, 1980).

Training programs could include a specialized intra-personal Compustress coping unit. This unit could include realization, articulation and analysis of computer fears. Trained behaviors could include writing and discussing computerphobia on a one-on-one or group basis as part of a broader computer training program. Knowledge, attitudes and skills are all part of a successful training program (Hersey and Blanchard, 1982).

A part of the computer apprehension reduction program could include formation of a "colleague system" of computer ability development on an each-one-teach-one basis. Colleagues could be matched on a knowledge/skill/attitudinal basis for a cascading chain of mentoring with one person being slightly ahead of another in a chain of increasing knowledge/skill/attitude toward computers. It has been noted that, "In such support systems, fear, anxiety and other stressors, may be discussed and dealt with in a professional manner (Martin and Gray, 1984, p. 280)."

Training programs with nearly an identical 
emphasis were found to be effective in reducing computer apprehension at statistically significant levels. Trainees with a business background were able to achieve statistically significant changes after a program to reduce communication apprehension by increased skills/knowledge and attitude (Nykodym and Simonetti, 1978; Nykodym and Ruud, 1985). Additional research is needed to determine if systematic programs of reduction of computer apprehension would achieve similar results. Meanwhile, this study suggests that the conclusions of Nykodym, Simonetti \& Christen (1988) can safely be generalized to a much broader population. Training and experience have a significant impact on Compustress.

\section{Table 1: Multiple Regression Analysis}

$\begin{array}{lccccc}\text { Source } & \begin{array}{l}\text { Sums of } \\ \text { Squares }\end{array} & \text { Mean square } & \text { F value } & \begin{array}{c}\text { Probability } \\ \text { of F }\end{array} \\ \text { Variables } & 2273.665 & 757.888000 & 9.654 & 0.0001 * \\ \text { Error } & 14994.622 & 78.505874 & & \\ \text { Total } & 17268.287 & & & & \end{array}$

Table 2: Analysis of Variables of User Hours and Training Hours

$\begin{array}{lccc}\text { Variable } & \begin{array}{c}\text { Parameter } \\ \text { Estimate }\end{array} & \begin{array}{c}\text { Standard } \\ \text { Error }\end{array} & \begin{array}{c}\text { Probability } \\ \text { of T }\end{array} \\ \begin{array}{l}\text { User hours } \\ \text { Hours of } \\ \text { training }\end{array} & 0.004176797 & 0.00104253 & 0.0001^{*} \\ \text { * Significant at the } .05 \text { level. } & 0.242460 & 0.106768 & 0.0243^{*}\end{array}$

\section{BIBLIOGRAPHY}

1. $\quad$ Bralobe, M., "Computer Anxiety Hits Middle Management," The Wall Street Journal, March 29, 1983.

2. $\quad$ Carroll, P.B., "The Tough Job of Training Computerphobic Managers," The Wall Street Journal, June 20, 1988 , p. 15.

3. $\quad$ Francis, R.M., "Do You Suffer From Cyberphobia?" Business Education Forum, February, 1983, p. 4.

4. Friedman, F.T., "Something There Is That Doesn't Love A Computer (Nor Hate It Either)," Library Journal, June 15, 1984.

5. $\quad$ Grobe, S.J., "Conquering Computer Cowardice," Journal of Nursing Education, 1984, 23, 232-239.

6. Hersey, P. and Blanchard, K., Management of Organizational Behavior: Utilizing Resources, Englewood Cliffs, Prentice-Hall, 1982.

7. Hollman, R.W., and Colley, B.J., "Overcoming Managerial Fears of Computers Through Planned Training," Personnel Administrator, 1984, 29-32.

8. Holmes, T. and Rahe, R., The Social Readjustment Rating Scale, Journal of Psychosomatic Research, 1967, 11, $212-218$.

9. James, F., "Got Vertigo Over Video Displays? Maybe It's A Case of Cyberphobia. The Wall Street Journal, June 8, 1982 , p. 37.

10. Lichtman, D., "Survey of Educators Attitudes Toward Computers," Creative Computing, 1979, 5, 48-50.

11. Martin, W.R. and Gray, R.A., "Computerphobia, Human Relations and Media Specialists: In-Service with a Full Head," International Journal of Instructional Media, 1984, 11, 277-283.

12. $\quad$ Naisbett, J., Megatrends, N.Y., Warner Books, 1982.

13. Nykodym, N., J.L. Simonetti \& J.C. Christen, Compustress: Analysis, Evaluation and Systems for Reducing the Fear of Computer Usage, (submitted for publication), 1988.

14. Nykodym, N. and Ruud, W.N., "Interview: Career Development Through Business Communication," Journal of Employment Counseling, 1985, 22, 149-155.

15. Nykodym, N. and Simonetti, J.L., "An Evaluation of Structured Experiences: How Effective is Experience-Based Learning?" Group \& Organization Studies: The International Journal of Group Facilitators, 1978, 3, 489-496.

16. Paul, L., "Research on Cyberphiliacs and Cyberphobiacs Reveals 30\% of Workers Fear Computers," Computer World, 4-5-82, p.14.

17. $\quad$ Penrose, R., "New Literacy," Science Digest, 1983, 91, 189-20.

18. Rout, L., "Computers: Many Managers Resist "Paperless" Technologies for Their Own Offices." The Wall Street Journal, June 24, 1982 , p. 1.

19. Schwartz, G.E., "Stress Management in Occupational Settings," Public Health Reports, 1980, 95, pp. 104-105.

20. Wysocki, B., "Automated Offices: Executives Discovered Computers," The Wall Street Journal, July 6, 1979, p. 1. 